\title{
Health Promotion Through Mass Media
}

\author{
Sandra L. Calvert \\ Georgetown University \\ Rodney R. Cocking \\ National Institute of Mental Health
}

People adopt behavioral patterns consistent with events observed in their environments, including television portrayals. Although television programs frequently portray unhealthy styles of living, a vast potential exists for people to learn healthy patterns of behavior from media presentations. The purpose of this article is to examine interactions between the person and television that capitalize upon environmental features associated with healthy life styles. In particular, we advance the hypothesis that people act upon media messages which advocate healthy life styles when they perceive the messages as personally relevant and when they believe that they can translate those messages into personal actions. The challenge for the television medium is to present content about healthy life styles in a manner that people can understand, remember, and which motivates them to act-either by altering unhealthy patterns of living (intervention) or by refusing to partake in these patterns in the first place (prevention).

\section{AGENTIC ACTION, SELF-EFFICACY, AND HEALTH}

When people believe that they can control the events around them, their health is enhanced (Bandura, 1986). Even institutionalized elderly people who control simple events like watering a plant improve their sense of well-being (Langer \& Rodin, 1976). Findings from diverse sectors suggest that health is promoted when people believe themselves to be active agents who control events that occur in their environments.

In social-cognitive theory, attention, retention, motivation, and behavior are regulated by self-efficacy, one's belief about personal control (Bandura, 1986). However, a person must have a sense of self in order to evaluate the outcomes of actions and to develop beliefs about how effective they are in those endeavors. In

Portions of this article were presented at the annual meeting of the American Psychological Association, San Francisco, August 1991.

Correspondence and requests for reprints should be sent to Sandra L. Calvert, Department of Psychology, Georgetown University, 37th and O. Streets NW, Washington, DC 20057. 
other words, for a person to have a sense of self-efficacy, that person must first have a perception of himself or herself as one who acts with intent, an agentic person. Agency refers to a person's capacity to manage his or her actions and an awareness that those actions have consequences which they can control (Harre, 1983), such as enhanced well-being. Based upon the evaluations of consequences for those agentic, intentional actions, a person develops beliefs about self-efficacy.

This shift from spectator to active participant is a fundamental extension of social-cognitive theory. The person presented in this model makes active decisions that shape his or her destiny, including decisions about healthy life styles. By such an account, events such as media influences are interpreted as active information processing, whereby a person acts upon content that is judged as personally relevant and that is in keeping with one's self-definition.

\section{EFFECTIVE DELIVERY OF MESSAGES}

Television viewers typically watch about 30 hours of programming weekly. In addition to programs, viewers are exposed to advertisements and to public service announcements, brief messages that are designed to promote healthy living styles. These various formats can serve as vehicles by which health-promoting messages can be transmitted to viewers. Some formats promote healthy living styles intentionally, as in the case of public service announcements, certain informational programs, some news segments, and a few advertisements; other formats support health unintentionally, as in the case of dramatic television programs.

Television presentations involve both content and form, or production features. The content involves the message of the broadcast. The form involves how that message is delivered, including production techniques like action, sound effects, music, and dialogue (Huston \& Wright, 1983).

Both content and form influence viewers' attention and memory of program messages. Content domains, like the comprehensibility of the message, influence whether viewers will attend to the message initially or on subsequent exposures. For example, viewers attend when they expect to understand the message, and they stop attending when the message is too difficult to comprehend (Anderson, Lorch, Field, \& Sanders, 1981). Form domains, which vary in perceptual salience, can either elicit or lose the attention and interest of viewers. For example, children use perceptually salient production techniques like sound effects to guide their attention to children's programs; narration in the absence of perceptually salient techniques, such as found in a news segment, is unlikely to elicit attention because children may judge that content as less relevant and less interesting to them (Huston \& Wright, 1983). Viewers make attentional decisions based upon the extent to which they perceive the content and form to be directed at them and relevant to them. That is, viewers develop 
schemas about the personal relevance of content and form, and they guide their attention accordingly.

If the message is to exist beyond its electronic transmission, the viewer has to engage in representational thinking related to the event. When this activity is delayed past the immediate viewing situation, the viewer must also remember the message. Comprehension and retention of program messages are active processes that are guided by a viewer's schemas. Thematic comprehension gradually emerges during middle childhood, but an understanding of concrete information occurs as early as the preschool years. Information that is targeted for viewers, then, must fit their particular cognitive capabilities if the message is to be effective.

For information to result in action, three additional components are involved: (a) A viewer must have the skill to produce the behavior; (b) a viewer must believe that he or she can perform the behavior (self-efficacy); and (c) a viewer must be motivated to act on that information, a condition that is enhanced when information is judged to be personally relevant. In the area of health promotion, action also includes a decision to inhibit behaviors by refusal to act in undesirable ways.

\section{INHIBITION OF UNHEALTHY LIFE STYLES}

What are the mechanisms that maintain unhealthy behavior, and what are the mechanisms involved in the control of behavior? Control processes like inhibition are key to this model. For example, people who engage in high-risk behaviors like smoking cigarettes, taking drugs, or partaking in sexual activity with multiple partners can be exposed to the danger of these activities via television programs, news segments, or public service announcements. If viewers decide that their personal behaviors place them at risk, they may decide to drop the activity from their repertoire. The implication is that control processes of maintenance or inhibition are influenced by multiple behavioral variables.

Dramatic television programs can convey information that results in viewer decisions to inhibit negative patterns of behavior. For instance, popular television characters can be cast in roles where they die of lung cancer because they smoke cigarettes or contract AIDS because of needle sharing or promiscuous sexual conduct. Although these types of portrayals are rarely seen in dramatic television, the potential for altering behaviors makes them obvious candidates for intervention strategies. This potential may be enhanced when viewers admire a television character or perceive a character as similar to themselves (Calvert, Cocking, \& Smrcek, 1991).

Public service announcements, a format uniquely suited to promote healthy living styles, target drug use, smoking, and AIDS prevention in vignettes that run $10 \mathrm{~s}$ to $1 \mathrm{~min}$. The effectiveness of campaigns, however, may vary as a function of message clarity to the target audience. Indeed, in a multinational 
study comparing AIDS public service announcements produced in the United States, Germany, and Austria, the target audience could not be identified, which diminishes the potential impact of the message on viewers. More importantly, most public service announcements about AIDS contained little content for comprehension, probably because of the sensitive nature of AIDS transmission (Calvert et al., 1991). The challenge in using this format is to present a message quickly in a manner that does not offend community standards. Although public service announcements hold promise as a way to transmit content that will inhibit risky actions of people, that promise will only be realized if messages inform viewers about specific actions they should and should not take.

\section{DISINHIBITION OF HEALTHY LIFE STYLES}

Some public service announcements about AIDS have focused attention on unwarranted public fears about how the disease is acquired (Calvert et al., 1991). Such messages can disinhibit people's fears about AIDS by demonstrating that the virus is not contracted by exposure to sneezes or coughs. Portrayals of filmed models who perform a feared activity efficaciously can reduce the anxieties of observers. Disinhibition of the healthy behavior occurs, in part, because the observer learns new strategies for controlling a fear (Bandura, 1986). In other words, the person learns that specific agentic actions will result in mastery of the situation rather than helplessness. These feelings of control promote better health.

Increasing prevalence of videotape recorders indicates that technologies will play important roles in disinhibiting viewer fears. For example, videotapes developed by groups like "Mr. Rogers' Neighbo hood" attempt to decrease children's fears of events like going to the hospital. Similarly, videotapes are available in doctors' offices to inform and to decrease the fears of those with medical problems like breast cancer. Videotapes allow effective narrowcasting to the specific target audience who is most likely to benefit from the information.

\section{RESPONSE FACILITATION OF HEALTHY LIFE STYLES}

Some behaviors that are in keeping with healthy living styles are low in frequency. For instance, many people may wear seat belts, but perhaps not every time, or only when driving their own cars and not as passengers. Television programs and public service announcements can affect the person here, too. In response facilitation, a model influences a person by increasing the number of times that the behavior is performed (e.g., wearing a seat belt whenever riding in a car).

In one series of public service announcements, wearing seat belts is the targeted activity. For example, two "dummies" ride in an automobile without seat belts and suffer the consequences of a wreck. If these "dummies" had actually chosen to wear their seat belts, we would have a response facilitation effect. 
Dramatic television programs rarely focus attention on life-enhancing actions like wearing seat belts. Rather, the thrill of fast-action car chases is the trend, where risking life and limb and engaging in life-threatening behavior is portrayed as desirable. Rarely are seat belts worn. When characters in more recent dramatic television programs buckle their seat belts, the behaviors are very subtle and are not labeled. Clearly, spontaneous use of seat belts in television programming is a step in the right direction. Connecting audiences to relevancy of low-frequency behavior, like use of seat belts, is the challenge.

Informational programs may well serve as a catalyst for health promotion. In exercise programs, for example, viewers are invited to participate with their hosts. Other programs educate viewers about healthy diets and disease prevention.

Because viewers selectively attend to information that they judge to be personally useful, producer-intended messages may be less important in guiding agentive action than is a detail that is judged to be central by the viewer. In this instance, informational programming may have unintended salutary effects for health promotion. The programming may serve as the impetus for adopting beneficial behaviors or propel the person toward a different attitude about the content. For example, the morning news program may include segments on weather, economic trends, entertainment, and a guest spot with a chef who whips up a recipe. Although the central theme of the program is news, and the core content of the special cooking segment may be a particular method for preparing chicken, incidental information in the form of processes or techniques (substitutes for fats and oils) can promote healthier diets. The viewer may shift the central theme of the message so that at a later point in time, she or he no longer remembers the particular chicken recipe; instead, the healthier ways to achieve the same results as cooking with creams and oils is remembered and applied to new recipes. For our purposes, this is not so much an example of incidental learning as an illustration of agentive action; that is, the viewer has redefined the theme of the media message and has internalized and acted upon it in terms of personal goals.

Even commercials designed to sell products can promote healthy living styles. Milk commercials, for instance, use animation and other attention-getting techniques to enhance children's attitudes toward drinking milk, a highly nutritious beverage. The theme of these commercials is "Milk-it does a body good." Repeated exposure to such messages may well increase children's consumption of milk in what is otherwise a predominantly vast wasteland of children's products.

\section{INFORMATION DELIVERY IN ECOLOGICAL SETTINGS}

Effective delivery of televised information about healthy life styles requires that targeted viewers see the message. Presentation of messages in home environ- 
ments is important because a mass audience is viewing. This process could be enhanced by presenting messages when the target group is likely to be viewing. Advertisers master this practice. By contrast, because public service announcements are aired free, they may be shown at any time. If both programs and public service announcements that are directed at the same audience were broadcast during the same time slot, effectiveness might increase.

Video cassette recorders can also refine the transmission of messages to targeted viewers. For instance, music stores intersperse AIDS public service announcements directed at adolescents within their rock videos (M. Kelly, personal communication, September 6, 1991). Similarly, media presentations can be used in school and work settings to educate people about drug and alcohol abuse. Such innovations in message dissemination increase the probability that targeted viewers will see the message, perceive that message as personally relevant, and ultimately act upon that message in a constructive manner.

\section{SUMMARY AND IMPLICATIONS FOR HEALTH PROMOTION}

Television is such a prevalent force in American homes that it has vast potential for influencing individuals' information, their understanding, and ultimately, their choices. Video recorders extend this range of influence both within the home and beyond the home into school, work, and recreational settings. The effectiveness of health-promoting media portrayals depends upon people's willingness to bring the messages to bear directly upon their lives through action. Getting people to see that the media environment provides choices through the options offered by being informed, in this sense, of healthy versus unhealthy choices, is the heart of agentive action. Behavioral studies indicate that the more control people take over their life choices, the more likely they will be to act in ways that are life-enhancing and healthy. The implication is that media like television should present responsible and comprehensible health-related messages. Media can foster attitudes about self-relevance, personal control, and personal choice. In this sense, media comprise an untapped set of environmental features that can alter the quality of life.

\section{REFERENCES}

Anderson, D.R., Lorch, E.P., Field, D.E., \& Sanders, J. (1981). The effects of tv program comprehensibility on preschool children's visual attention to television. Child Development, 52, $151-157$

Bandura, A. (1986). Social foundations of thought and action: A social cognitive theory. Englewood Cliffs, NJ: Prentice-Hall.

Calvert, S.L., Cocking, R., \& Smrcek, M. (1991). AIDS public service announcements: A paradigm for behavioral science. Journal of Applied Developmental Psychology, 12, 255-267.

Harre, R. (1983). Personal being. Oxford: Blackwell.

Huston, A.C., \& Wright, J.C. (1983). Children's processing of television: The informative functions 
of formal features. In J. Bryant \& D.R. Anderson (Eds.), Children's understanding of television: Research on attention and comprehension (pp. 35-68). New York: Academic.

Langer, E., \& Rodin, J. (1976). The effects of enhanced personal responsibility for the aged: A field experiment in an institutional setting. Journal of Personality and Social Psychology, 34, 191198. 